waves) is given alongside a good general account of tides and storm surges. Coastal upwelling, too, is lucidly analysed, and this part of the book ends with a list of 16 penetrating comments on features that contribute to the puzzling nature of Eastern boundary currents.

Two chapters which follow indicate the special features of the atmosphere-ocean system in the tropics and in mid-latitudes. The ocean's equatorially trapped waves are analysed, along with equatorial undercurrents. The important vertically propagating waves in the equatorial atmosphere are related - like all the dynamical features covered in the book to clear observational data establishing their significance. The special characteristics of the SW Monsoon winds of the Indian Ocean and the variable ocean currents which they generate are excellently treated. The very different characteristics of mid-latitude motions are seen as in part due to the enormous frequency separation between internal waves and planetary waves. Consequences for the time-scale of an ocean's response to changing wind stress are analysed and related to the characteristics of Western boundary currents such as the Gulf Stream and the Kuroshio. This is another section where the quasi-geostrophic approximation is found to be most fruitful. In the atmosphere, the Eliassen-Palm Flux of energy, in the direction of a certain wave group velocity, is found to be a most powerful mechanism for feeding the jet stream.

The last chapter outlines the crucial large-scale instabilities that are needed in the atmosphere to provide the angular momentum flux which the general circulation demands. The author's description of the crucial barotropic and baroclinic instabilities is particularly well done, and leads to the outline of the life-cycle of a baroclinic disturbance such as a midlatitude cyclone or (say) one of the ocean eddies that peel off from the Gulf Stream. Frontogenesis is described both in the atmosphere and in the ocean. Finally, the Eliassen-Palm Flux is seen as generating simultaneously the required transport of energy and of angular momentum consistent with the latitudinal distribution of surface winds.

In all, Dr Gill has demonstrated the great value of an exposition on this subject by an author equally proficient in both meteorology and physical oceanography. His book will be indispensable to those who would like to learn about both the extremely complicated, observed data on the atmosphere and ocean, and the ways in which modern fluid dynamics can be used to illuminate them. Those ways are most impressive even though they are still incomplete. As Dr Gill observes in his final sentence, "nature is complex and there is much to be learned!".

Sir James Lighthill is Provost of University College London.

\section{Are sons worth more than daughters?}

\section{Kenneth B. Armitage}

\section{Red Deer: Behaviour and Ecology of} Two Sexes.

By T.H. Clutton-Brock, F.E. Guinness and S.D. Albon.

Edinburgh University Press/University of Chicago Press: 1983. Pp.400. Hbk £20; pbk £9.75, \$12.95.

A RECENT article in Science 83 asked why men are bigger than women. The answers provided were speculative and characteristic of much contemporary writing in sociobiology and evolutionary biology in which every difference, every behaviour, has an $a$ posteriori adaptive explanation. Not all the pitfalls of speculative interpretation are avoided in this book, but overall it represents a significant advance in the emerging sub-discipline of behavioural ecology.

The authors sought to "examine the evolutionary causes and ecological consequence of sex difference'" in the red deer, especially that of size and reproduction. Each individual attempts to maximize its reproductive success. The behaviour, ecology and consequences associated with this strategy not only reflect differences among individuals, but also differences between sexes.

In the studies described in the book, the variance in lifetime reproductive success was greater among males than females. Hinds invested more in their sons before weaning; sons are born heavier, require a longer gestation period and suckle more frequently than do daughters. As evolutionary theory predicts that, overall, investment will be equally divided between sons and daughters, it was expected that slightly fewer of the more "expensive" sons would be produced - there should be a slight bias towards females in the sex ratio. As it turned out, the bias was towards males. To reconcile observations and theory, the authors suggest that investment was equalized by a greater post-weaning investment in daughters. Daughters stay with their mothers after weaning and use the same feeding area, apparently at a cost to the mother.

Looking at investment in sons or daughters in this way does not, however, take into account the longer term pay-offs. Increased direct fitness requires grand offspring and the fitness pay-off for one successful son - who can fertilize many females - may equal that of several daughters. Before we can formulate appropriate models of sex ratios we need to know the probabilities of producing reproductively successful sons and daughters. In general, however, the book lacks a thorough treatment of kinship and of its relationship to reproductive success, to the movement of hinds between harems and to population growth. Kinship needs to be understood before coming to the conclusion that scramble competition for resources occurs among females. Female groups are matrilines; if resources are too widely distributed to be easily defended, fitness could be enhanced by sharing resources with kin. Is it the sharing of resources that leads to the formation of groups rather than danger from predators? If that is the case, eventually population increase could lead to competition among kin. How will that competition be expressed?

I especially enjoyed the chain of relationships demonstrated repeatedly throughout the book. For example, although fighting among stags is costly, fighting ability determines harem size and reproductive success; body size, a consequence of early growth, in turn determines fighting ability. In cold winters, however, large size may be detrimental, male mortality exceeding that of females. Does winter stress act as a counter-

\section{IMAGE UNAVAILABLE FOR COPYRIGHT REASONS}

selection against increasing male size? Again, variation in the lifetime reproductive success of hinds was more a consequence of calf survival than of fecundity. Hinds did not select particular stags as mates other than avoiding immature stags. Birth weight of calves affected summer survival, but birth date was a better predictor of winter survival.

Although it was pointed out a decade ago that male and female strategies may differ and even conflict, this book makes a major contribution in thoroughly documenting the importance of treating each sex separately when analysing the evolutionary ecology of a species. Further, the authors have clearly demonstrated that a long-term research effort will be needed in order to replace adaptationist stories with rigorous statistical analysis of competing hypotheses.

Kenneth B. Armitage is Professor of Systematics and Ecology at the University of Kansas. 